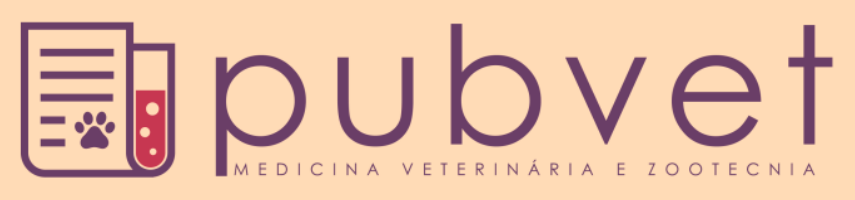

https://doi.org/10.22256/pubvet.v12n1a18.1-8

\title{
Pesquisa de Babesia spp. e Ehrlichia spp. em cães assintomáticos, atendidos no Hospital Veterinário da Universidade Federal do Piauí
}

Sávio Matheus Reis de Carvalho ${ }^{1 *} \bullet$, Wenderson Rodrigues de Amorim ${ }^{2} \bullet$, Mariane Vieira de Sá $^{\ominus}$, Iuri Santana de Oliveira ${ }^{2}$, Isael de Sousa Sá ${ }^{\bullet}$, Lygia Silva Galeno ${ }^{3}$ Raylson Pereira de Oliveira ${ }^{4}{ }^{\circ}$, Márcio Eduardo de Melo Benvenutti ${ }^{5}$, Márcia Paula Oliveira Farias ${ }^{6}{ }^{\ominus}$, Antônio Augusto Nascimento Machado Júnior ${ }^{60}$

${ }^{I}$ Discente em Universidade Federal do Piauí, Campus Profa. Cinobelina Elvas. Bom Jesus - PI. Brasil

${ }^{2}$ Discente em Universidade Federal do Piauí, Departamento de Medicina Veterinária. Bom Jesus - PI. Brasil.

${ }^{3}$ Discente em Universidade Estadual do Maranhão, Campus Paulo VI. São Luís-MA. Brasil. E-mail: lygiagaleno@outlook.com

${ }^{4}$ Residente em Medicina Veterinária pela Universidade Federal Rural de Pernambuco, Campus Recife, PE. Brasil.

${ }^{5}$ Patologista Clínico Veterinário, Universidade Federal do Piauí, Campus Profa. Cinobelina Elvas, Bom Jesus-PI.

${ }^{6}$ Docente da Universidade Federal do Piauí, Campus Profa. Cinobelina Elvas, Bom Jesus-PI. Brasil. E-mail: machadojunior@gmail.com

*Autor para correspondência, E-mail: savioreis1995@gmail.com

RESUMO. O presente trabalho teve como objetivo pesquisar os hemoparasitas Babesia spp. e Ehrlichia spp. em cães assintomáticos atendidos no Hospital Veterinário da Universidade Federal do Piauí, campus de Bom Jesus. Para isso, foram coletadas amostras de sangue da veia cefálica e da ponta da orelha para realização de hemograma e esfregaço sanguíneo para pesquisa dos hemoparasitas em 30 animais que não apresentavam sinais clínicos das doenças. Os resultados demonstram que dos 30 animais avaliados, em 1 (3,3\%) foi constatado a presença de Babesia spp. no esfregaço de sangue periférico. Em nenhum dos animais foi encontrado Ehrlichia spp., logo, não ocorreu casos de coinfecção. No hemograma constatou-se anemia em 18/30 (60\%) animais, sendo 82,3\% de anemia normocítica normocrômica, 5,9\% de anemia microcítica normocrômica, 5,9\% de anemia normocítica hipocrômica e 5,9\% de anemia macrocítica hipocrômica; além disso observouse em 50\% dos casos trombocitopenia, em $20 \%$ pancitopenia, $20 \%$ de leucopenia e $16,7 \%$ de leucocitose, sendo $10 \%$ de neutropenia, $13,3 \%$ neutrofilia, $30 \%$ eosinofilia, $20 \%$ eosinopenia, $16,7 \%$ linfocitose, $20 \%$ linfocitopenia, 3,3\% de monocitose e, 3,3\% de monocitopenia. Este estudo observou a baixa sensibilidade do exame parasitológico de ponta de orelha em animais assintomáticos, frente ao diagnóstico de hemoparasitoses, pois apenas um animal mostrou-se positivo para Babesia spp., mesmo existindo indício no hemograma que sugerissem a presença subclínica do mesmo. Deste modo, mesmo não encontrando o agente na lâmina, não se pode descartar a possibilidade do animal ter o parasita. Sendo assim sugere-se a utilização de testes mais sensíveis, como a reação em cadeia da polimerase (PCR), reação de imunofluorescência indireta (RIFI) e EnzymeLinked Immunosorbent Assay (ELISA).

Palavras chave: animais, babesiose, erliquiose, hemograma, hemoparasitas

\section{Search for Babesia spp. and Ehrlichia spp. in asymptomatic dogs, attended at the Veterinary Hospital of the Federal University of Piaui}

ABSTRACT. The present work had as objective to investigate the hemoparasites Babesia spp. and Ehrlichia spp. in asymptomatic dogs treated at the Veterinary Hospital of the Federal University of Piauí, Bom Jesus campus. For this purpose, blood samples from the 
cephalic vein and the ear tip were collected for hemogram and blood smear to investigate hemoparasites in 30 animals that showed no clinical signs of the diseases. The results show that of the 30 evaluated animals, in 1 (3.3\%) Babesia spp. in the peripheral blood smear. In none of the animals was Ehrlichia spp., Therefore, no cases of coinfection occurred. Anemia was observed in 18/30 (60\%) animals, $82.3 \%$ of normochromic normocytic anemia, $5.9 \%$ of normocyclic microcytic anemia, $5.9 \%$ of hypochromic normocytic anemia and $5.9 \%$ of anemia macrocítica hypochromic; Thrombocytopenia was present in 50\% of cases, pancytopenia $20 \%$, leucopenia $20 \%$ and leukocytosis $16.7 \%$, $10 \%$ neutropenia, $13.3 \%$ neutrophilia, $30 \%$ eosinophilia, $20 \%$ eosinopenia, 16, $7 \%$ lymphocytosis, $20 \%$ lymphocytopenia, $3.3 \%$ of monocytosis, and $3.3 \%$ of monocytopenia. This study observed the low sensitivity of the parasitological exam of the ear tip in asymptomatic animals, in view of the diagnosis of hemoparasitosis, since only one animal was positive for Babesia spp., Even if there was a hemogram indicating the subclinical presence of the same. Thus, even without finding the agent on the slide, one can not rule out the possibility of the animal having the parasite. Therefore, the use of more sensitive tests such as polymerase chain reaction (PCR), indirect immunofluorescence (IFR) and Enzyme-Linked Immunosorbent Assay (ELISA) is suggested.

Keywords: animals, babesiosis, erythemia, blood count, hemoparasites

\section{Investigación de Babesia spp. y Ehrlichia spp. en perros asintomáticos, atendidos en el Hospital Veterinario de la Universidad Federal de Piauí}

RESUMEN. El presente trabajo tuvo como objetivo investigar los hemoparasitos Babesia spp. y Ehrlichia spp. en perros asintomáticos atendidos en el Hospital Veterinario de la Universidad Federal de Piauí, campus de Bom Jesús. Para ello, se recogieron muestras de sangre de la vena cefálica y de la punta de la oreja para realizar hemograma y frotis sanguíneo para la investigación de los hemoparasitos en 30 animales que no presentaban signos clínicos de las enfermedades. Los resultados demuestran que de los 30 animales evaluados, en $1(3,3 \%)$ se constató la presencia de Babesia spp. en el frotis de sangre periférica. En ninguno de los animales se encontró Ehrlichia spp., Por lo que no hubo casos de coinfección. En el hemograma se constató anemia en 18/30 (60\%) animales, siendo $82,3 \%$ de anemia normocítica normocrómica, 5,9\% de anemia microcítica normocrómica, $5,9 \%$ de anemia normocítica hipocrómica y 5,9\% de anemia macrocítica hipocrómica; además de esto se observó en 50\% de los casos trombocitopenia, en $20 \%$ pancitopenia, en $20 \%$ de leucopenia y un $16,7 \%$ de leucocitosis, siendo un $10 \%$ de neutropenia, un $13,3 \%$ neutrofilia, un $30 \%$ eosinofilia, un $20 \%$ de eosinopenia, $16,7 \%$ linfocitosis, $20 \%$ linfocitopenia, 3,3\% de monocitosis y 3,3\% de monociopenia. Este estudio observó la baja sensibilidad del examen parasitológico de punta de oreja en animales asintomáticos, frente al diagnóstico de hemoparasitosis, pues sólo un animal se mostró positivo para Babesia spp., Aun existiendo indicio en el hemograma que sugiere la presencia subclínica del mismo. De este modo, aunque no se encontré el agente infeccioso en la lámina, no se puede descartar la posibilidad del animal tener el parásito. Por lo tanto, se sugiere la utilización de pruebas más sensibles, como la reacción en cadena de la polimerasa (PCR), reacción de inmunofluorescencia indirecta (RIFI) y Enzyme-Linked Immunosorbent Assay (ELISA).

Palabras clave: animales, babesiosis, erliquiosis, hemograma, hemoparasitas

\section{Introdução}

As hemoparasitoses são enfermidades de distribuição cosmopolita e com grande importância na medicina veterinária, são provocadas mais comumente por protozoários do gênero Babesia spp. e por ricketisia do gênero Ehrlichia spp. A transmissão ocorre pelo carrapato Rhipicephalus sanguíneos, no momento do repasto sanguíneo (Mundim et al., 2008). 
As bactérias do gênero Rickétsias a qual pertence à Erlhichia canis são classificadas como microrganismos intracelulares obrigatórios, pleomóficos, gram-negativos, que parasitam as células brancas do sangue (Ettinger \& Feldman, 2004). A babesiose que acomete canídeos domésticos está associada à Babesia canis, Babesia vogelli e Babesia rosse. São parasitas de hemácias, e estão frequentemente relacionado a anemia (Nelson \& Couto, 2015). Essas doenças são causas de vários transtornos para os tutores de cães, pois, quando se desenvolvem levam a um quadro clínico que fragiliza muito o animal, necessitando de auxílio veterinário e muitas vezes de internação (Labarthe et al., 2003).

O cão pode conviver com esses hemoparasitas sem a manifestação de sinais clínicos compatíveis com a existência destas, entretanto, qualquer agravo que leve o animal a ter uma queda imunológica pode ser suficiente para desencadear a doença (Mehlhorn et al., 1980).

O diagnóstico das hemoparasitoses pode ser realizado baseado nos sinais clínicos e por meio do esfregaço sanguíneo, onde é observada a presença do parasita (Nelson \& Couto, 2015). Outros exames, que confirmem o agente etiológico estão disponíveis como a citologia, sorologia e métodos moleculares (Caprariis et al., 2011).

Diante da importância dessas hemoparasitoses e do diagnóstico precoce dessas afecções, o objetivo do presente trabalho foi pesquisar os hemoparasitas Babesia spp. e Ehrlichia spp. em cães assintomáticos atendidos no Hospital Veterinário da Universidade Federal do Piauí, campus de Bom Jesus.

\section{Material e Métodos}

O presente trabalho foi realizado no Hospital Veterinário da Universidade Federal do Piauí, campus de Bom Jesus, utilizando-se 30 cães oriundos dos atendimentos clínicos da rotina do hospital.

Os critérios de inclusão do animal no trabalho foram não apresentar sinais clínicos compatíveis com a existência de hemoparasitose. Os critérios de exclusão foram, por conseguinte, animais que tenham manifestações clínicas condizentes com hemoparasitoses, tais como epistaxe, febre, vômito, diarreia.

Após a seleção dos animais e durante o atendimento clínico foi coletada uma gota de sangue periférico da ponta da orelha. Dessa amostra foram confeccionadas três lâminas por meio de esfregaço sanguíneo, as quais foram remetidas para o Laboratório de Parasitologia para serem coradas pela técnica do panótico rápido. As leituras das lâminas foram realizadas sobre microscopia de luz, na objetiva de 100x.

Para a realização do hemograma completo, foram coletados $2 \mathrm{~mL}$ de sangue por venopunção da veia cefálica ou jugular. O intuito foi avaliar o quadro hematológico dos animais. No momento da coleta realizou-se a antissepsia local com álcool iodado a $10 \%$. As amostras coletadas foram depositadas em tubos de ensaio contendo EDTA a $10 \%$. Foram homogeneizadas, e posteriormente levadas para o Laboratório de Patologia Clínica, onde foram analisadas. No laboratório realizou-se novamente homogeneização, e logo após, deu-se início ao hemograma. Preencheu-se $2 / 3$ de um capilar com sangue, e com uma gota realizou-se o esfregaço sanguíneo para a diferenciação de leucócitos, contagem de plaquetas, observando-se a morfologia eritrocitária além de pesquisar a presença dos hemoparasitas. Vedou-se o micro capilar com massa de modelagem para que o mesmo não vaze, então, o mesmo foi levado à microcentrifuga a 11 mil RPM por 5 minutos, depois foram levados para leitura do hematócrito em cartão de leitura apropriado.

A lâmina confeccionada foi corada pela técnica do panótico rápido deixando 10 segundos no álcool fixador, retirando-se o excesso, posteriormente colocando-se 10 segundos no corante I (corante ácido) e 20 segundos no corante II (corante básico), lavando em água corrente e aguardando secar.

Para análise da hemoglobina, com auxílio de uma micropipeta monocanal colocou-se $5 \mathrm{ML}$ da amostra em 1,250 ML de solução de Drabkin e homogeneizou-se, esperou-se 5 minutos e procedeu-se a leitura no aparelho bioquímico.

Para contagem das hemácias, utilizou $2 \mathrm{~mL}$ de solução fisiológica e 10 microlitros da amostra, em seguida homogeneizou-se a solução e preencheu-se um dos lados da câmlara de Neubauer. Utilizando o microscópio óptico, na objetiva de 40x, contaram-se os quadrados periféricos e o central do quadrado grande ao centro. Cada quadrado médio possui 16 pequenos quadrados, onde se contou na forma de "L" invertido, somaram-se as hemácias dos 5 quadrantes e multiplicou-se pelo fator de $10 \mathrm{mil}$. 
Para estimar leucócitos utilizou-se 200 microlitros de solução de Turck e 10 microlitros da amostra homogeneizou-se. Preencheu-se a câmara de Neubauer e utilizando microscópico óptico na objetiva de 10x contou--se os 4 quadrados grandes das extremidades, sendo a contagem feita em "L" invertido. Somaram-se os resultados dos 4 quadrados e multiplicou-se pelo fator 50 .

A lâmina corada foi utilizada para a leucometria diferencial, contando-se em forma de torre, 100 leucócitos; logo em seguida se realizou a estimativa de plaquetas, contando-se as plaquetas presentes em 10 campos do esfregaço no momento da leitura, tirou-se uma média e o resultado foi multiplicado pelo fator $20 \mathrm{mil}$.

\section{Resultados e Discussão}

Dos 30 animais avaliados, em um foi constatado a presença de Babesia spp. em esfregaço de sangue periférico (ponta de orelha). Em nenhum dos animais foi encontrado Ehrlichia spp., logo, não ocorreu casos de coinfecção (Tabela 1).

Tabela 1. Porcentagem de animais positivos e negativos com base no teste parasitológico de ponta de orelha

\begin{tabular}{lcc}
\hline Parasitas & Positivo, $\%$ & Negativo, $\%$ \\
\hline Babesia spp. & 3,3 & 96,7 \\
Ehrlichia spp. & 0,0 & 100 \\
Coinfecção & 0,0 & 100 \\
\hline
\end{tabular}

$\mathrm{O}$ alto percentual de animais negativos junto ao teste de ponta de orelha, pode ser justificado pelo fato que na pesquisa foram utilizados animais assintomáticos, e mesmo estes, estando infectados por hemoparasitas, apresentavam baixa parasitemia não permitindo a identificação do parasita. Outro fato, é que o exame parasitológico direto, embora seja um exame altamente conclusivo para o diagnóstico das hemoparasitoses, apresenta pouca sensibilidade, mesmo em casos de doença clínica, principalmente nas fases crônicas (Costa, 2011).

Encontrou-se 3,3\% de animais positivos para Babesia spp, condizente com valor encontrado por Silva et al. (2012) de 3,3\% de animais positivos provenientes da área rural de Imperatriz, área urbana de Governador Edison Lobão, e do município de Davinópolis. Barcellos et al. (2011) encontraram $46,7 \%$ de animais positivos na cidade
Passo Fundo - RS. O baixo percentual encontrado, pode ser devido ao fato do trabalho ter sido realizado utilizando-se animais assintomáticos, os quais não apresentam níveis de parasitemia consideráveis.

Em nenhum dos animais foi encontrado Ehrlichia spp., logo nenhuma coinfecção foi constatada, diferindo dos resultados encontrados por Costa (2011) que foram 6,7\% de Ehrlichia canis e 34,6\% de coinfecção, na cidade de Goiânia. Segundo Costa (2011), a identificação de mórulas de Ehrlichia spp. em esfregaço sanguíneo é difícil, devido à baixa parasitemia, sem também explicado pela baixa porcentagem de células infectados que dificilmente ultrapassa $1 \%$. $\mathrm{Na}$ erliquiose canina apenas em $4 \%$ dos casos é encontrada a mórula nos monócitos. Isso pode ser o motivo pelo qual não foram encontrados casos de coinfecção uma vez que pesquisa foi voltada apenas para Babesia spp. e Ehrlichia spp.

Constatou-se anemia em 18 dos 30 animais pesquisados, o que corresponde a $60 \%$ do total. Resultado semelhante foi encontrado por Canuto et al. (2016) cujo índice foi de $60,7 \%$ em animais com Ehrlichia spp., Canuto et al. (2016) observaram anemia em 70,4\% dos animais acometidos por Babesia spp., os quais eram provenientes de atendimentos da Unidade Hospitalar Veterinária da Universidade Estadual do Ceará. A anemia é um achado clínico bastante comum nos casos de hemoparasitoses. A cidade de Bom Jesus - PI é uma área endêmica para essas enfermidades. $\mathrm{O}$ alto percentual de animais anêmicos pode ser devido os mesmos estarem sendo acometidos por hemoparasitas, onde não podem ser descartadas outras enfermidades que também causam anemia como é o caso da leishmaniose, uma vez que os dados do hemograma são sugestivos e não conclusivos.

Dos 17 animais que se apresentaram anêmicos, houve uma predominância de anemia normocítica normocrômica correspondendo a 82,3\% dos casos. Machado (2004) encontrou em seu trabalho um número inferior de animais com essa alteração o qual foi de $41,1 \%$. Esse tipo de alteração eritrocitária é frequentemente observado em casos de erliquiose canina. Sendo sempre considerada uma alteração que pode ser causada por outras enfermidades como doenças inflamatórias e doenças que causam hipoplasia ou aplasia da medula (Machado, 2004, Mundim et al., 2008). 
Tabela 2. Médias, Desvio padrão, Mínimo, Máximo e, valores de referência do eritrograma, leucograma e plaquetograma dos cães pesquisados para hemoparasito.

\begin{tabular}{|c|c|c|c|c|c|}
\hline Itens avaliados & Média & Desvio Padrão & Mínimo & Máximo & Valor de referência \\
\hline Hemácias $\left(\times 10^{6} / \mathrm{mm}^{3}\right)$ & 5.065 .957 & 1556459,47 & 2.000 .000 & 7.839 .000 & 5.500 .000 a 8.500 .000 \\
\hline Hemoglobina (g/dL) & 11,3 & 3,4 & 4,9 & 17 & 12 a 18 \\
\hline Hematócrito (\%) & 35 & 10,32 & 16 & 53 & 37 a 55 \\
\hline VCM (fl) & 69 & 5,24 & 57 & 80 & 60 a 77 \\
\hline $\mathrm{CHCM}(\%)$ & 33 & 1,14 & 30 & 35 & 31 a 35 \\
\hline Plaquetas $\left(\times 10^{3} / \mu \mathrm{L}\right)$ & 197.700 & 118162,70 & 24.000 & 482.000 & 200.000 a 500.000 \\
\hline Leucócitos totais & 11.549 & 6136,18 & 2.888 & 33.760 & 6.000 a 17.000 \\
\hline Neutrófilos segmentados, $\mathrm{x} 10^{3} / \mu \mathrm{L}$ & 7.585 & 5487,22 & 1.791 & 31.395 & 3.000 a 11.500 \\
\hline Eosinófilos $\left(\mathrm{x} 10^{3} / \mu \mathrm{L}\right)$ & 853 & 940,58 & 0 & 4.209 & 100 a 1.200 \\
\hline Basófilos $\left(\mathrm{x} 10^{3} / \mu \mathrm{L}\right)$ & 0 & 0 & 0 & 0 & Raro \\
\hline Monócitos $\left(\times 10^{3} / \mu \mathrm{L}\right)$ & 491 & 366,22 & 85 & 1.365 & 100 a 1.300 \\
\hline Linfócitos $\left(\times 10^{3} / \mu \mathrm{L}\right)$ & 2.622 & 2256,29 & 249 & 9. 284 & $1.000 \mathrm{a} 4.800$ \\
\hline
\end{tabular}

$\overline{\mathrm{VCM}}=$ volume corpuscular médio; $\mathrm{CHCM}$ = concentração de hemoglobina corpuscular média, Valor de referência segundo Jain \& Jain (1993).

Verificaram-se também casos de anemias microcítica normocrômica $(5,9 \%)$ e normocítica hipocrômica $(5,9 \%)$, dos animais. Diferindo do valor relatado por Albernaz et al. (2007) que encontraram $11,4 \%$ de anemia normocítica hipocrômica em animais positivos para Ehrlichia canis. Essas alterações podem estar sendo causadas por várias enfermidades, sejam elas de punho infeccioso e não infeccioso, ou eritropoiese ineficiente (Stockham \& Scott, 2011).

Outra alteração hematológica encontrada foi a anemia macrocítica hipocrômica, a qual foi observado em 5,9\% dos animais. Concordando com o resultado encontrado por Albernaz et al. (2007) em animais acometidos por erliquiose canina que foi de 5,9\%. Esse achado é comumente visto em animais acometido por Babesia spp., como também em casos de hemólise induzida por infecções bacterianas e virais (Stockham \& Scott, 2011).

Segundo Mundim et al. (2008), nos casos de erliquiose, a anemia apresentada é devido a lesão medular causada pelo parasito, que resulta em diminuição da resposta medular. A hemólise intra ou extravascular é bastante encontrada em animais acometidos por babesiose, sendo a resposta imunológica o mecanismo mais importante na patogenia desta enfermidade, sendo a anemia bastante comum nesses casos (Irwin, 2005; Weiss \& Wardrop, 2010).

Em 50\% dos casos os animais apresentaram trombocitopenia, resultado condizente com o encontrado por (Meneses et al., 2008) onde foi evidenciado em $60 \%$ dos animais positivos para
E. canis. Canuto et al. (2016) observaram resultado superior em seu trabalho com índice de $92,6 \%$ de trombocitopenia em animais acometidos por Babesia canis. A trombocitopenia é uma alteração hematológica observado com frequência em casos de Erliquiose, devido a destruição plaquetária causada pelo sistema de defesa autoimune (Weiser et al., 1991), com redução da sobrevida e da capacidade de agregação (Mendonça et al., 2005). Já no caso da Babesiose a trombocitopenia pode ser justificada pela ocorrência de coagulação intravascular disseminada que pode ter como fatores predisponentes a hemólise (Canuto et al., 2016).

A pancitopenia se fez presente em seis animais, ou seja, em $20 \%$ dos casos. Valor menor foi descrito por Albernaz et al. (2007) onde encontraram pancitopenia em 10,1\% dos cães acometidos por erliquiose canina. Fato esse, justificado pela ação do parasita, o qual causa supressão medular, causando muitas vezes a diminuição do número de todos os elementos figurados do sangue ( $\underline{\text { Sainz et al., 2000, }}$ Oliveira et al., 2000).

$\mathrm{Na}$ série branca, $16,7 \%$ dos animais apresentaram leucocitose e $20 \%$ leucopenia. Resultados diferentes foram descritos por Hirschmann (2012) que observou 21,7\% das amostras com leucocitose e 1,4\% leucopenia. Canuto et al. (2016) encontraram leucopenia em $51,85 \%$ dos casos e, leucocitose em 7,41\% em animais positivos para babesiose canina. $\mathrm{O}$ aumento no número de leucócitos pode ser explicado pelo fato do animal apresentar alguma 
infecção, necrose tecidual e severa inflamação. Já os casos de leucopenia são mais comuns em doenças virais, bacterianas maciça, drogas tóxicas e em casos de neoplasia medular (Ettinger \& Feldman, 2004).

Observou-se em 10\% dos animais uma diminuição no número de neutrófilos segmentados indicando neutropenia e em 13,3\% apresentaram neutrofilia. Discordando com os valores encontrados por Hirschmann (2012) que foram de $1,4 \%$ e $2,9 \%$ respectivamente. Casos de animais com alterações neutrofilicas, geralmente são causados por infecções virais como a pavovirose, como também por protozoários e bactérias, nos casos de toxoplasmose e erliquiose, além de necrose e estresse (Stockham \& Scott, 2011).

Em relação aos eosinófilos, registraram-se eosinofilia em $30 \%$ e eosinopenia em $20 \%$ dos casos. No estudo de Hirschmann (2012) foram encontrados valores menores em animais errantes no Rio Grande do Sul, sendo esses valores de 8,7 $\%$ para eosinofilia, e 2,9\% para eosinopenia. Segundo Thrall (2007) a eosinofilia é o aumento no número de eosinófilos circulantes, sendo uma alteração comumente causada por distúrbios parasitários, hipersensibilidade ou lesão incomum. Já a eosinopenia pode ser causada pela adrenalina, mas a forma mais comum na clínica é devido à ação dos corticosteroides, além de estresse e exercícios intenso (Kerr, 2003).

Dos cães, $16,7 \%$ apresentaram linfocitose e $20 \%$ linfocitopenia. Dados diferente foram relatados por Albernaz et al. (2007) onde encontraram $3,2 \%$ e $17,4 \%$ respectivamente. A linfocitose corresponde ao aumento no número de linfócitos na circulação, a qual em cães pode ser causada por erliquiose canina, doença de chagas, leishmaniose, babesiose e hipersensibilidade. A linfocitopenia vem sendo frequentemente descrita como uma alteração hematológica importante da erliquiose canina, principalmente na fase aguda da doença (Oliveira et al., 2000, Castro et al., 2004).

A porcentagem apresentada tanto para monocitose quanto para monocitopenia foi de $3,3 \%$. Albernaz et al. (2007) relataram monocitose em $10,1 \%$ e monocitopenia em $28,0 \%$. As alterações monocíticas são comumente causadas infecções, distúrbios imunomediados, idade avançada, neoplasias (Ettinger \& Feldman, 2004).

O animal positivo para Babesia spp. no exame parasitológico de ponta de orelha, e no hemograma, apresentou as seguintes alterações hematológicas, diminuição no número de hemácias, diminuição da hemoglobina e hematócrito, leucopenia e trombocitopenia. Muitos dos animais apresentaram resultados semelhantes no hemograma mesmo sendo negativos no exame parasitológico, assim não se pode descartar a possibilidade desses animais estarem infectados, uma vez que os mesmos apresentaram alterações sugestivas de hemoparasitas. O método parasitológico de ponta de orelha apresenta alta especificidade, no entanto, menor sensibilidade, uma vez que os microrganismos podem não ser visualizados, devido à reduzida parasitemia (Vidotto et al., 2001); assim a utilização de teste como o PCR se faz necessários, por ser uma técnica extremamente sensível, que detecta o material genético do microrganismo, Esse teste é mais utilizado com fins de pesquisa, devido seu alto preço.

\section{Conclusão}

Este estudo observou a baixa sensibilidade do exame parasitológico de ponta de orelha em animais assintomáticos, frente ao diagnóstico de hemoparasitoses, pois apenas um animal mostrouse positivo para hemoparasita, mesmo existindo indício no hemograma que sugerissem a presença subclínica do mesmo. Deste modo, mesmo não encontrando o agente na lâmina, não se pode descarta a possibilidade do animal ter o parasita. Sendo assim sugere-se a utilização de testes mais sensíveis, como o PCR, RIFI e ELISA.

\section{Referências Bibliográficas}

Albernaz, A. P., Miranda, F. J. B., Júnior, O. A. M., Machado, J. A. \& Fajardo, H. V. 2007. Erliquiose canina em Campos dos Goytacazes, Rio de Janeiro, Brasil. Ciência Animal Brasileira, 8, 799-806.

Barcellos, H. H. A., Melatti, L., Linck, C. M., Gavioli, F. B., Quadros, A. M., Palma, M. D., Casagrande, G., Oro, G., Valle, S. F. \& Motta, A. C. 2011. Aspectos clínicos e laboratoriais em cães com babesiose crônica. Congresso Brasileiro de Medicina Veterinária. Florianópolis.

Canuto, F. J. C., Matias, A. L. M. \& Cortez, A. A. 2016. Achados hematológicos de cães positivos para babesiose em fortaleza, Ceará. IV Congresso Estudantil de Medicina Veterinária da UECE. Ciência Animal, Fortaleza, Ceará. 
Caprariis, D., Dantas-Torres, F., Capelli, G., Mencke, N., Stanneck, D., Breitschwerdt, E. B. \& Otranto, D. 2011. Evolution of clinical, haematological and biochemical findings in young dogs naturally infected by vector-borne pathogens. Veterinary Microbiology, 149, 206212.

Castro, M. B., Machado, R. Z., Aquino, L. P. C. T., Alessi, A. C. \& Costa, M. T. 2004. Experimental acute canine monocytic ehrlichiosis: clinicopathological and immunopathological findings. Veterinary Parasitology, 119, 73-86.

Costa, H. X. 2011. Interação de hemoparasitos e hemoparasitoses em casos clínicos de trombocitopenia em cães no município de Goiânia. Departaamento de Veterinária. Universidade Federal de Goiás, Goiânia, Goiás.

Ettinger, S. \& Feldman, E. 2004. Tratado de medicina interna veterinária: doenças do cão e do gato. Guanabara Koogan, Rio de Janeiro.

Hirschmann, L. C. Padrões hematológicos de cães errantes provenientes de seis municipios do rio grande do sul. Monografia (Medicina veterinária) - Universidade Federal Rural do Semi-Árido. Porto Alegre - RS, 2012.

Irwin, P. J. 2005. Babesiosi sand cytaux zoonosis. In Shaw, S.E., Day, M.J. (Eds), Arthropod borne infectious diseasesofthedogand cat. Manson Publishing, Barcelona, p. 63-77.

Jain, N. C. \& Jain, A. H. 1993. Essentials of Veterinary Hematology, 1st edn. WileyBlackwell, Davis, CA, USA.

Kerr, M. G. 2003. Exames laboratoriais em medicina veterinária: bioquímica clínica $e$ hematologia. Roca, São Paulo.

Labarthe, N., Campos, P. M., Barbarini, O., McKee, W., Coimbra, C. A. \& Hoskins, J. 2003. Serologic prevalence of Dirofilaria immitis, Ehrlichia canis, and Borrelia burgdorferi infections in Brazil. Veterinary Therapeutics: Research in Applied Veterinary Medicine, 4, 67-75.

Machado, R. Z. 2004. Erliquiose canina. Revista Brasileira de Parasitologia Veterinária, 13, 53-57.

Mehlhorn, H., Schein, E. \& Voigt, W. P. 1980. Light and electron microscopic study on developmental stages of Babesia canis within the gut of the tick Dermacentor reticulatus. The Journal of Parasitology, 66, 220-228.
Mendonça, C. S., Mundim, A. V., Costa, A. S. \& Moro, T. V. 2005. Erliquiose canina: Alterações hematológicas em cães domésticos naturalmente infectados. Bioscience Journal, 21, 167-174.

Meneses, Í. D. S., Souza, B. M. P. S., Teixeira, C. M. M. \& Guimarães, J. E. 2008. Perfil clínicolaboratorial da erliquiose monocítica canina em cães de Salvador e região metropolitana, Bahia. Revista Brasileira de Saúde e Produção Animal, 9, 770-776.

Mundim, E. C. S., Francisco, M. M. S., Souza, J. N., Alencar, M. A. G. \& Ramalho, P. C. D. 2008. Incidência de hemoparasitoses em cães (Canis familiares) de rua capturados pelo Centro de Controle de Zoonoses (CCZ) da cidade de Anápolis-GO. Ensaios e Ciência: Ciências Biológicas, Agrárias e da Saúde, 12, 108-114.

Nelson, R. W. \& Couto, C. G. 2015. Medicina interna de pequenos animais. Elsevier Editora, Amsterdan.

Oliveira, D., Nishimori, C. T., Costa, M. T., Machado, R. Z. \& Castro, M. B. 2000. AntiEhrlichia canis antibodies detection by "DotELISA" in naturally infected dogs. Revista Brasileira de Parasitologia Veterinária, 9, 15.

Sainz, A., Tesouro, M. A., Amusategui, I., Rodriguez, F., Mazzucchelli, F. \& Rodriguez, M. 2000. Prospective comparative study of 3 treatment protocols using doxycycline or imidocarb dipropionate in dogs with naturally occurring ehrlichiosis. Journal of Veterinary Internal Medicine, 14, 134-139.

Silva, A. B., Costa, A. P., De Sá, J. C., Costa, F. B., Santos, A. C. G. \& Rita de Maria, S. N. C. 2012. Detecção molecular de Babesia canis vogeli em cães e em Rhipicephalus sanguineus na mesorregião do oeste maranhense, nordeste brasileiro. Ciência Animal Brasileira, 13, 388395.

Stockham, S. L. \& Scott, M. A. 2011. Fundamentos de patologia clínica veterinária, Rio de Janeiro.

Thrall, M. A. 2007. Hematologia e Bioquímica Clínica Veterinária. Editora Roca, São Paulo.

Vidotto, O., Morais, H. S. A. \& Dagnone, A. S. 2001. Animal and human Ehrlichiosis/\&60; br\&62; Erliquiose nos animais e no homem. Semina: Ciências Agrárias, 22, 191-201. 
Weiser, M. G., Thrall, M. A., Fulton, R., Beck, E. R., Wise, L. A. \& Van Steenhouse, J. L. 1991. Granular lymphocytosis and hyperproteinemia in dogs with chronic ehrlichiosis. The Journal of the American Animal Hospital Association, 27, 84-88.

Weiss, D. \& Wardrop, K. 2010. Schalm's Veterinary Hematology. 6 ed. Singapore: Wiley Black well, 1232p.
Aticle History:

Received 22 September 2017

Accepted 11 October 2017

Available online 28 November 2017

License information: This is an open-access article distributed under the terms of the Creative Commons Attribution License 4.0, which permits unrestricted use, distribution, and reproduction in any medium, provided the original work is properly cited. 